\title{
O processo de formação do atleta de futsal e futebol: análise etnográfica
}

CDD. 20.ed. 796.07

796.33
Fernando Renato CAVICHIOLLI*

Aline Barato CHELUCHINHAK*

André Mendes CAPRARO*

Wanderley MARCHI J UNIOR*

Fernando Marinho MEZZADRI*
*Departamento de Educação Física, Universidade Federal do Paraná.

\section{Resumo}

Apesar de o senso comum estabelecer que todo brasileiro "já nasce sabendo jogar bola", é longo o caminho entre o reconhecimento de se "ter talento" para o futebol até a "lapidação" desta espécie de "aptidão aparentemente inata". Assim, cada vez mais cedo, as crianças praticam Futsal em escolinhas esportivas com a esperança de que sejam encaminhadas/convidadas a jogarem o Futebol em clubes profissionais. Como a quantidade desses jovens que se lançam no mercado esportivo é crescente, faz-se necessário observar e entender como se dá o comportamento social estabelecido nas escolinhas de futsal/futebol. 0 objetivo do presente estudo foi investigar o planejamento/ações que pais e clubes realizam para que os garotos adquiram a capacidade de jogar futsal/futebol. Para tanto, por meio de trabalho etnográfico, durante um ano foram observadas e registradas em entrevistas e diário de campo as práticas e as falas dos jovens atletas, pais, professores e dirigentes de um clube tradicional de Curitiba. Partindo da premissa de que a mítica do talento inato dá lugar à aprendizagem sistematizada como forma de se obter o triunfo, pretendemos expor aqui como são traçados os caminhos e os descaminhos no mundo do futsal e futebol de base. 0 trabalho revela que a formação de um jogador consiste num processo de ensino-aprendizagem-prática determinado pelos pais e que encontram eco em clubes especializados. Evidencia-se que para alguns pais e professores o "jogar bola" é apenas mais uma possibilidade de profissão, tão desejada, entre outras.

Unitermos: Futsal/futebol de base; Talento; Planejamento familiar e pedagógico.

\begin{abstract}
Madrugada do dia 21 de março de 1980. Noite mágica. Nascia um dos maiores jogadores que a história já viu. Mas isso era apenas o começo. Ronaldo Assis Oliveira: o mais novo dos filhos de João e Miguelina. Na infância, o principal brinquedo era a bola, a melhor diversão, o futebol. Indicado pelo irmão Assis, que já brilhava no futebol profissional, aos sete anos de idade, Ronaldinho iniciou na escola de futebol infantil do Grêmio Football Porto Alegre. Naquela época, Assis, que hoje é empresário do jogador, garantia que o mais novo membro da família Oliveira jogava mais que qualquer outro. Atleta diferenciado que era, logo começou a brilhar...”'
\end{abstract}

\section{Introdução}

O aprendizado do futebol no Brasil sempre esteve atrelado ao significado cultural de sua prática, isto é, desde a infância os brasileiros são influenciados por esse significado. Antes de aprender a andar, as crianças recebem bolas e uniformes de times, são incentivadas a assistir partidas de futebol pela televisão e frequentar estádios. Quando se aprende a andar, aprende-se a jogar em qualquer lugar onde uma bola possa, ou não, rolar, quicar e ser chutada. E assim, a expressão "jogar bola" torna-se uma 
identificação sumariamente privativa da prática do futebol (Freire, 1998).

Apesar de o senso comum estabelecer que todo brasileiro "já nasce sabendo jogar bola", é longo o caminho entre o reconhecimento de se "ter certo talento" para o futebol - nos círculos familiares e escolares - até a "lapidação" desta espécie de "aptidão aparentemente inata" - nos clubes especializados ${ }^{2}$. Se a criança, futuramente, tiver sucesso em seu desempenho, seu esforço será convertido em recompensa monetária. Em casos específicos, tais recompensas podem atingir proporçôes astronômicas. Para se ter uma ideia desse argumento e das perspectivas de globalização no futebol, basta analisar os índices de rentabilidade nas transações de jovens atletas profissionais para o exterior com os investimentos tradicionais no mercado econômico. Enquanto a venda dos atletas Henrique Buss (21 anos) do Palmeiras para o Barcelona, Breno Borges (19 anos) do São Paulo para o Bayern de Munique, Maurício Peruchi (19 anos) do Fluminense para o Villareal renderam, respectivamente, $195,4 \%, 2.300 \%$ e $320 \%$ para seus clubes em menos de seis meses, no ano de 2008 a poupança rendeu apenas $7,9 \%$, os Fundos DI 12,11\%, o dólar 31,94\%, o ouro $32,13 \%$, as ações da Petrobrás $-46,11 \%$ e as ações da Vale $-51,13 \%{ }^{3}$.

Este é o desejo de muitos garotos e uma realidade para poucos. E para os que conseguem chegar ao final do processo de "lapidação", como Ronaldinho, é preciso aprender a lidar com as especificidades da futura profissão.

Considerando a constatação de que a quantidade de jovens que se lançam neste mercado de trabalho no Brasil é crescente, julgamos necessário observar e entender o comportamento social estabelecido nas escolinhas de futsal/futebol no que diz respeito especificamente ao planejamento de uma futura carreira. Dentre as diversas variáveis que influenciam no processo de desenvolvimento de um atleta, as interferências advindas das interrelaçōes sociais constituem aspectos fundamentais no estabelecimento de condições favoráveis para o processo de formação dos pequenos futebolistas. Além disso, MASSA (2006) cita que a busca de talentos tem apoiado-se em fatores subjetivos, pelos quais os profissionais que atuam nessa área utilizam como instrumento de detecção, seleção e promoção de talentos a própria experiência e intuição, e que implica em mais uma variável que pode interferir no processo de formação. A seleção de um "futuro" talento muitas vezes ocorre na forma da tentativa e do erro, buscando chegar a um caminho próximo do que estes profissionais "acham" correto, mesmo que muitas vezes os instrumentos utilizados sejam baseados em um modelo empírico de detecção e avaliaçãa.

Os escritos pioneiros de Elias e Dunning a partir da década de 60 - que tardiamente chegaram ao Brasil por meio de Roberto DaMatta (1982) e Simoni GUEDES (1982), entre outros - serviram como referenciais das dissertaçôes e teses que se multiplicaram na década de 90. No início desse século surgiram vários trabalhos versando acerca da relação interdependente entre o futebol e a formação profissional, em alguns casos como tema central, já em outros, como temas de aporte secundário, tendo como fim discutir amplamente o futebol. Como exemplo, podemos citar: "Circulação e imigração de atletas brasileiros" (RIAL, 2004), "Projetos familiar e ascensão social por meio do futebol" (SouZA, 2008), "Formação de jogadores" (DAmo, 2005) e "Produção social do jogador de futebol” (Rodrigues, 2007).

Esses trabalhos, assim como as críticas que produziram, procuraram não ignorar a complexidade do fenômeno social futebol, causando um efeito positivo na área das Ciências Sociais e, sobretudo, da Educação Física. A Educação Física ao iniciar o trânsito pelas Ciências Sociais não desloca seu foco da intervenção direta da performance, da participação na fisiologia, do "marketing", mas apenas amplia seu leque de discussão. DAMO aponta que:

sob a influência de certas vertentes de cunho marxista, como a Escola de Frankfurt, a artilharia antidesportiva denunciou os abusos que certos líderes políticos fizeram do esporte com a colaboração da mídia especializada e a subserviência de atletas e de espectadores. Esta crítica, por vezes corrosiva, por vezes superficial, por ignorar a complexidade do fenômeno social ou pelo uso estereotipado de certos conceitos (como alienação, por exemplo), produziu, mesmo assim, efeitos muito positivos no âmbito de disciplinas como educação física (DAmO, 2005, p.10).

Com a intensificação dos estudos sobre o futebol nos últimos anos, a importância da formação de atletas para os clubes é apontada em diferentes áreas. $\mathrm{Na}$ Educação Física, por exemplo, o trabalho de Proni (2000) discutiu a modernização do futebol profissional e demonstrou que a adoção de métodos empresariais é produto da difusão da indústria do entretenimento e da globalização. Na mesma área mas voltado para gestão do desporto - CAMPESTRINI (2009) discutiu as questôes que permeiam a responsabilidade social e verificou se as mesmas se aplicam ou não nas políticas e procedimentos 
das principais agremiações do futebol brasileiro no desenvolvimento do trabalho de formação de atletas. Já na área sociológica, Rodrigues (2003, p.7) apresenta dois trabalhos, o primeiro abordando a formação do jogador de futebol, desnaturalizando a profissão como resultado apenas de vocação ou dom; no segundo trabalho, amplia e aprofunda a discussão sobre o fim da lei do passe e a construção de um "habitus" no futebol brasileiro, desde as categorias de base. Na Antropologia DAmo (2005, p.14) estuda o futebol espetáculo a partir do processo de formação de atletas profissionais, "[...] trata-se de uma etnografia tendo como objeto principal os dispositivos usados na conversão de jovens talentos em atletas aptos a performances em forma de espetáculo".

O presente estudo (Registro no CEP - Biológicas 029-06), aprovado no dia 5 de dezembro de 2006 pelo
Comitê de Ética do Setor de Ciências Biológicas da Universidade Federal do Paraná conforme a resolução CNS 196/96 - que trata das diretrizes e normas regulamentadoras de pesquisas em seres humanos - teve como objetivo investigar o planejamento e ações que pais e clubes realizam para que os garotos adquiram a capacidade de jogar futsal e futebol. Partimos da premissa de que a mítica do talento inato dá lugar ao longo processo de planejamento familiar e recorrência aos clubes para a aprendizagem sistematizada como forma de se obter o triunfo.

Cabe ressaltar que nossa ideia não é julgar se os critérios de iniciação e especialização esportivas adotados pelo clube e pelas famílias são corretos ou não. $\mathrm{O}$ que pretendemos aqui é expor como são traçados os caminhos e os descaminhos no mundo do futsal e futebol de base.

\section{Métodos}

Existe aqui a consciência de que o futsal e o futebol tornaram-se, com o passar do tempo, esportes diferenciados, sobretudo, do ponto de vista do alto rendimento, tanto no plano tático como nas regras, nos sistemas ou na parte técnica. Por outro lado, do ponto de vista da iniciação esportiva com crianças, pode-se perceber uma similaridade de desenvolvimento, partindo-se do pressuposto de que o futebol e o futsal são "jogos de bola com os pés". Desta forma, essa "similaridade" entre o futebol e o futsal, a liado ao fato de não existirem muitas opções de campos de várzea, têm direcionado as crianças e os jovens a primeiramente praticar o futsal em escolas e escolinhas esportivas para que, mais tarde, sejam encaminhados ou convidados a jogarem o futebol em clubes profissionais. Além disso, "o desejo do público de ver performances esportivas cada vez mais refinadas" (DAMO, 2005) exige dedicação intensa, fazendo com que pais e familiares procurem esses locais para a aprendizagem formal em idades cada vez mais tenras ${ }^{4}$.

Para a realização do estudo utilizamos como apoio metodológico o livro etnográfico de Norbert Elias - Os estabelecidos e "Outsiders" (Elias \& SCOTSON, 2000). Nesta obra Elias busca - entre relatórios oficiais, observações e entrevistas - alcançar um ponto de vista de como é estruturada uma figuração social, e assim, compreender a natureza dos laços de interdependência que unem ou separam os indivíduos. Além dessa, o texto tem como referência outra obra de EliAS (1995), Mozart: a sociologia de um gênio, cuja temática extraí justamente o embate sobre a questão do talento nato e o trabalho extenuante da criança. Elias parte do exemplo de Mozart, que já tinha um ofício a partir dos três anos de idade. Apoiando-nos no referencial sociológico de Norbert Elias, inserimo-nos em um tradicional clube curitibano que desenvolve a modalidade de futsal (considerada pelos pais como essencial e mais produtiva que o futebol de campo em idades iniciais) para meninos a partir dos cinco anos de idade.

Para a realização da pesquisa, de cunho sócioantropológico, foram utilizados dois instrumentos concretos: o diário de campo e as entrevistas. O primeiro instrumento da pesquisa qualitativa configura-se como o mais importante instrumento da Antropologia. A construção do diário de campo foi realizada através da etnografia do grupo estudado. VelHo (1975) indica que a tradição antropológica traz, entre outras características, a valorização do trabalho de campo com o contato próximo, direto e relativamente prolongado com grupos, comunidades e segmentos sociais. Pretende-se, com isso, ir além da superficialidade e das aparências, procurando captar os significados da ação social e buscando perceber as visóes de mundo que se associam às identidades e desempenhos. Mas não são essas coisas, as técnicas e os processos determinados, que definem o empreendimento. O que o define é o tipo de esforço intelectual que ele representa: um risco elaborado para uma descrição densa. Assim sendo, a antropologia se realiza na etnografia. 
O segundo instrumento da pesquisa qualitativa foi a entrevista semi-estruturada, que é definida “[...] quando o instrumento de coleta está pensado para obter informações de questôes concretas, previamente definidas pelo pesquisador, ao mesmo tempo em que permite que se realizem exploraçôes não previstas, oferecendo liberdade ao entrevistado para dissertar sobre o tema ou abordar aspectos que sejam relevantes sobre o que pensa" (NEGrini, 2004, p.74). Portanto, ela dá ao entrevistado e ao entrevistador, uma abertura para que outros assuntos sejam inseridos durante a conversa, conforme o andamento da resposta do indivíduo. Para responder a elas foram selecionados dois diretores do clube de acordo com a necessidade de contemplar os objetivos do trabalho.

Os dados coletados através das entrevistas presenciais foram transcritos "verbatim", procurando garantir a confiabilidade dos dados, preservando assim as ideias tais como elas foram expressas pelos participantes. O conteúdo das entrevistas foi utilizado somente após a permissão do participante, através do Termo de Consentimento Livre e Informando.

Ainda como procedimento metodológico, foram observadas as práticas (tanto nos treinos quanto nos jogos) e registradas em um diário de campo as falas dos pais (três pais por categorias), das crianças das categorias compreendidas entre cinco e 13 anos (total de 48 crianças) e dos três professores que acompanham essas equipes. $\mathrm{O}$ critério foi selecionar os três atletas de cada categoria que há mais tempo pertenciam àquele clube e seus respectivos pais. Foram 35 itens selecionados para a observação dos atletas, pais e treinadores, dentre os quais podemos destacar: a política de recrutamento, o planejamento na área

\section{Resultados}

A fase da infância e o início da adolescência são circundados por um regime de treinamento metódico bastante severo, sendo que, nesse processo dinâmico, as formas de conduta predominantes aprendidas e não aprendidas, inclinam-se fortemente em favor da primeira, por meio de trabalho exaustivo ${ }^{5}$. Ao examinar mais cuidadosamente estes anos de aprendizagem, observa-se evaporar ante olhos atentos o conceito de que o talento inato para o futebol está presente desde o início, materializado naqueles que chegaram ao triunfo, independente das experiências motoras a que foram submetidos. Assim também, os gestos motores aprendidos não escolar e da saúde, imposição de padrões pela família, o planejamento do clube, a formação profissional dos professores e necessidade de aprofundamento. Essa pesquisa de campo ocorreu tanto nas arquibancadas, lanchonete e restaurante do clube como em eventos festivos, torneios e festas de aniversários. Foram feitas três observaçôes semanais, por dois dos pesquisadores. Nas categorias sub 13 e sub 11 foram três treinos semanais totalizando 216 possíveis observaçôes durante o ano. Nas categorias sub 7 e sub 9 foram dois treinos semanais. A soma total de dias de treino das categoriais foi de 318. Participamos de 97 desses encontros. Isso representa 30,65\% e mais 22 jogos ao longo do ano. No transcorrer do ano, pelo campeonato metropolitano, a categoria sub 7 fez 12 jogos, sub 9 fez 23 jogos, sub 11 e 13 fizeram 18 jogos cada uma delas, totalizando 71 partidas.

As entrevistas se limitaram aos dois administradores do clube. Continham 12 questôes previamente elaboradas, divididas em blocos, tais como: formação profissional, planejamento de açōes, parte pedagógica dos treinamentos, recrutamento de atletas, política de manutenção, informaçôes de infra-estrutura, no total de 15 perguntas. Participações em outras atividades de observação, como conversas em lanchonetes e aniversários não ultrapassaram 21 encontros, na sua grande maioria ocorreram após as partidas realizadas no próprio clube.

No texto estão contidas as falas dos atores sobre o mundo do futsal e do futebol de campo, planejamento e educação. Os nomes dos garotos apresentados no texto são fictícios, e quando seus pais são citados nos referimos primeiro ao nome do garoto. Os professores foram identificados apenas com números. estão indissoluvelmente ligados às peculiaridades de vida de cada um desses garotos a que se aplicam os adjetivos de talentosos ou geniais.

A crença de que os garotos que nasceram no Brasil com o "dom" de jogar futebol é parcialmente aceita por alguns pais, crianças e professores. Por outro lado, significativa parcela de pais e professores acredita que o "dom" - embora presente nos discursos e nos jargões populares - é relativo. Sendo assim, o desenvolvimento dos garotos é mais centralizado numa tendência que permeia a lógica da produção, isto é, há um planejamento dos pais (mesmo que difuso) e professores na formação da criança-atleta e da criança-cidadão. 
Partimos, então, da premissa que o fato da busca pelo clube esportivo já se configura como indicativo de planejamento esportivo da família em longo prazo para as crianças. Portanto, locais públicos (ruas e praças) ou o espaço escolar não são considerados pelos pais como adequados à evolução nesta área. Tal premissa aponta para uma possível inversão de valores: a mítica do talento inato dá lugar à aprendizagem sistematizada como forma de se obter o triunfo. Para se ter uma ideia sobre o assunto e suas diferentes opiniōes, em entrevista ao Jornal Nacional, dia 21 de janeiro de 1999, Edson Arantes do Nascimento (Pelé), considerado por muitos como o maior jogador de futebol do mundo, declarou que "futebol não se aprende", reforçando a crença que já se nasce no Brasil sabendo jogar futebol (SCAGLIA, 1999, p.35) ${ }^{6}$.

Por mais que o futebol tenha incorporado o léxico do mercado, da ciência, do trabalho e de outros campos afeitos à seriedade do mundo adulto, não é demais ressaltar que as performances atléticas destinam-se ao entretenimento, à excitação e a sociabilidade do seu amplo e diversificado público.

A ação de levar as crianças para os clubes e suas respectivas escolinhas de futebol ou turmas de treinamento sempre foi iniciativa dos pais. $\mathrm{Na}$ verdade, na sua grande maioria, foi exclusivamente do pai, sob o incentivo de parentes ou do professor de educação física da escola onde o menino estuda.

Essa inserção ocorre por diferentes razões que envolvem o planejamento do processo de aprendizagem/ futuro traçado pelas famílias em relação aos filhos e sua inclusão na sociedade: a) vestir a camisa de um clube e participar de uma equipe é essencial para a sociabilidade, destacando a necessidade de pertencimento a determinado grupo; b) é importante a integração social com diferentes camadas da população brasileira, ou seja, filhos de empresários estabelecendo relações com filhos de médicos, jornalistas, militares, motoristas, pedreiros, entre outros, formando, assim, um espaço multicultural e de co-habitação, essencial na integração e rivalização (que, segundo os pais, interferem na formação da personalidade da criança); c) os treinamentos de futsal nos clubes são rígidos e disciplinados, e, consequentemente, contribuem para formação de cidadãos responsáveis; e d) o talento inato que parece existir nestas crianças deve ser desenvolvido, oportunizado por meio de métodos já testados em outras crianças que, após anos de treinamento, neste mesmo clube, destacaram-se em grandes clubes do Brasil.

Há, entretanto, um fio condutor implícito nas razões enunciadas pelos pais. A questão que orgulha a todos eles é justamente a constatação de que os filhos têm talento, ou, como é expresso literalmente em conversas entre os pais: "[...] o meu filho leva jeito para jogar futebol” (Diário de Campo, 25 /11/2007). Isso faz com que os pais se realizem pessoalmente; pois alguns relataram a falta de oportunidade na sua infância, o que inviabilizou a possibilidade de terem sido grandes jogadores. $\mathrm{Na}$ concepção iluminista, a questão do gênio - e, consequentemente, a do talento - era posta em termos de um dom natural, um legado ocasional da natureza.

Nas palavras de KANT (1974):

Gênio é o talento (dom natural) que dá à arte a regra. Já o talento, como faculdade produtiva inata do artista, pertence, ele mesmo, à natureza. [...] Poderíamos também exprimir-nos assim: $\mathrm{O}$ gênio é um favorito da natureza, tal que só se pode considerá-lo como um fenômeno raro; o seu exemplo, para outras boas cabeças, produz uma escola, isto é, uma instrução metódica segundo regras, na medida em que se tenha podido extraí-las daqueles produtos do espírito e de sua peculiaridade; e, para estas, a bela-arte é, nessa medida, imitação, à qual a natureza, através do gênio, deu a regra."7

Até início do século XIX, não existia ainda a ideia do gênio como indivíduo, isto é, não havia a referência ao indivíduo como o possuidor de um dom divino especial. A concepção posterior de gênio como indivíduo extraordinário - a noção de sujeito de raro talento, com consciência singular do processo artístico - é uma ideia romântica. Somente no romantismo o gênio tornou-se o indivíduo espetacular que, no livre e deliberado exercício de seu talento pessoal, rompendo com os limites do seu tempo, quebra os padrōes e extrapola a ordem, fazendo avançar as formas de expressão e criando novas condições a partir das quais os outros possam recomeçar, abrindo caminho para que outro indivíduo genial rompa com o estabelecido ${ }^{8}$.

Quando detectado o talento, há uma difícil decisão que os pais têm que tomar: qual é o local mais adequado para o desenvolvimento dessa genialidade? Nota-se que a rede de sociabilidade da família ligada ao seu capital cultural e econômico ${ }^{9}$ é decisiva para tal escolha. Enfim, um gênio e futuro craque do futebol não podem começar simplesmente no campinho do bairro ou em qualquer time de escola. A opção de aprendizagem logo recai no clube, e este não pode ser qualquer clube: "tem que ter pedigree" - termo usado por um pai (Diário de Campo, 18/02/2008). Então, algumas questões entram em cena: quantos atletas o clube revelou nos últimos anos? Quantas vezes o clube foi campeão em 
competiçôes oficiais? Como é a estrutura física e a formação dos profissionais (há uma supervalorização se o professor no passado atuou em clubes do futebol)? Qual o valor das aulas e em quantos dias da semana os treinamentos ocorrem? Entre outras também cruciais na escolha do clube. Neste processo decisório e de aprendizagem dos pais e familiares, nota-se que o imaginário social é complexo e multifacetado. Porém, com uma concepção bem definida há sempre alguém que vê no talento o caminho mais rápido para criança (e quiçá da família e seus agregados) ter sucesso profissional e pessoal.

Nas diversas observaçōes acerca das conversas entre os pais e em alguns momentos entre as próprias crianças, especificamente quando se comparam entre si, em síntese, aparece a ideia de que uma pessoa habilidosa poderá desenvolver melhor a parte tática e técnica do futebol. Assim, segundo os pais, crianças e professores, se alguém tem talento para jogar futebol, então, este deve ser potencializado, isto é, elementos do universo do futebol como chutar, tocar, matar a bola no peito, na coxa, com os pés, entre outros, devem ser lapidados. Existem outros elementos que aparecem principalmente na forma dos técnicos se expressarem. Estes podem ser sintetizados no diálogo do professor 1 com um dos pais: "[...] talento alguns deles têm, mas temos que provocar situaçôes, criar exercícios onde o talento apareça [...] mas nada vai adiantar se o garoto não tiver persistência, muita vontade, disciplina e também ser humilde." (Diário de Campo, 13/05/2008). Entre os elementos contidos na fala do professor, sua somatória explica, em parte, como a criança talentosa consegue prosseguir e como outras desistem no transcurso. E também como algumas crianças nem tanto talentosas conseguem progredir com o auxílio dos profissionais. Talento ganha vida, torna-se concreto e visível ao ser coligado a alguns elementos que pais e professores consideram honrados (persistência, vontade de aprender, garra). É neste momento que a criança começa a trilhar seu caminho ao triunfo.

Alguns dos pais, em conversas informais, invocam que o talento do filho é algo herdado (hereditário), pois no passado a família teve algum parente que "levava jeito para jogar bola"; outros acreditam que o talento é genético (Diários de Campo, 27/11/2007; 12/04/2008; 17/05/2008; 31/05/2008). Segundo eles, isso os diferenciava dos demais garotos que com a mesma idade não tem desempenho semelhante a dos "escolhidos", isto é, aqueles que receberam este "dom divino" (Diário de Campo, 04/12/2007). $\mathrm{Na}$ verdade, o dom divino é um objeto de crença, e alguns dos atores observados direcionam seus discursos tecendo um amalgamento entre habilidade inata e adquirida.

Quando alguns pais chegam ao clube pesquisado para assistir o treinamento da equipe principal da categoria correspondente a idade do seu filho considerado até então pelo próprio pai como talentoso, é nítido o desconforto e até o constrangimento a que são expostos. A primeira constatação é a de que o gênio e talentoso filho irá precisar se esforçar muito para adquirir o mesmo padrão de jogo dos demais que estão na equipe há mais tempo. O pai de $\mathrm{Carlos}^{10}$ (sete anos) comentou com um outro pai:

desde muito pequeno o meu garoto apresentava facilidade nos fundamentos do futebol, chutava com precisão e dominava a bola como poucos na idade dele [...] mas vendo esses garotos da equipe do Clube da mesma idade jogando [...] não há comparação. Eles são muito mais rápidos no raciocínio e na velocidade de execução (Diário de Campo, 18/02/2008).

As dúvidas dos pais prosseguem, pois o clube, tão bem recomendado, não tem uma grande estrutura física e o linguajar dos professores não é tão polido como no ambiente escolar. Contudo, há pontos positivos que contam a favor sob determinada ótica: foram campeões por diversas vezes em diferentes categorias, os professores têm formação superior, alguns atuaram em grandes clubes do futebol profissional, formaram alguns atletas que se destacam no futsal e futebol de campo nacionalmente e internacionalmente, têm uma rede de contatos com diversos clubes de futebol do Brasil e com alguns clubes de futsal na Itália e Espanha (Diário de Campo, 25/02/2008).

$\mathrm{Na}$ sequência outro constrangimento foi observado. Um dos pais descobre que o número de crianças escolhidas para participar da equipe representante do Clube na Série Ouro já foi escolhido no ano anterior $^{11}$. Portanto, cabe a ele encaminhar seu filho às escolinhas de futebol que o próprio clube mantém. Nota-se uma diferença entre a equipe principal de cada categoria e as escolinhas de futebol: na equipe estão os garotos selecionados e considerados mais habilidosos; já nas escolinhas estão os garotos iniciantes, que não participam de campeonatos oficiais e têm que pagar pelas aulas.

Assim, os ex-talentosos começam sua caminhada dentro do clube. Não há um tempo específico para ascender à equipe. Primeiro, os meninos terão que se esforçar nas aulas e se destacar. Isso não é um processo totalmente planejado pelos pais, essa fase do aprendizado, inicialmente, não parecia necessária para alguns 
deles e para algumas crianças que simplesmente pensavam que iam jogar/brincar, e não treinar. A grande maioria dos ex-talentosos sofre grande pressão ${ }^{12}$. Um erro de fundamento, um exercício - por vezes complexo - não entendido desperta a fúria do treinador (Diário de Campo, 04/03/2008). A mãe de Marcos (nove anos) não se conformou com as palavras de baixo calão e o mau humor que tinha como alvo seu filho, vivia reclamando com os outros pais... " [...] tudo que ocorre de errado nas aulas, acaba sendo culpa do Marcos, esse professor é muito exigente" (Diário de Campo, 06/05/2008).

O plano da família de Marcos era que ele fosse um centroavante profissional. Porém, após semanas de treinamentos, ficou nítido o desinteresse da criança pelo esporte. Certa vez, nos intervalos do treinamento Marcos disse: "eu detesto futebol e detesto esse monte de exercícios, só venho aqui para jogar no gol, assim não preciso correr muito". Alguns meses depois, o treinador de Marcos confidenciou aos outros pais que a intenção do Clube era revelar talentos, e isso, segundo ele, não surge por acaso,

[...] veja só aquele gordinho, o Marcos, não adianta, ele nem gosta de correr, de saltar, de pular, e os pais querem que ele seja jogador. A mãe um dia veio falar comigo e me indagou por que o filho sempre levava algumas broncas. Então respondi que enquanto estivesse dando atenção ao filho dela, seria para a família não se preocupar, ele poderia seguir em frente [...] Bom, achei que poderia abreviar o sofrimento do garoto, e parei de dar atenção a ele (Diário de Campo, 19/06/2008).

Marcos ficou no Clube durante seis meses. Neste período, durante os treinamentos procurava se esquivar dos exercícios. Hoje, segundo os colegas do clube, pratica aulas de violão e judô em outro clube da cidade.

O planejamento familiar, em alguns casos, é difuso e muito superficial, mas para grande maioria que procurou o Clube, as etapas no futsal/ futebol de campo estão bem definidas. No primeiro ano as crianças devem frequentar as escolinhas de futebol e se esforçar o máximo para se destacar. Constatou-se que, em alguns casos, os pais levavam os seus filhos para outras quadras no Clube em dias diferentes dos treinos, procurando, na medida do possível, repetir os exercícios executados em quadra pelo treinador. Foi o caso dos irmãos Bruno e Breno. Enquanto Bruno (11 anos) treinava com a equipe da Série Ouro, seu irmão, Breno (sete anos), era submetido pelo pai a um treinamento rigoroso: "Ele ainda não está no mesmo nível dos demais goleiros da equipe de sete anos, mas pode ser titular... Ele tem que ser mais rápido e tem que aprender melhor o tempo de bola" - comentou com um dos pais (Diário de Campo, 07/04/2008). $\mathrm{O}$ treinamento ocorreu por mais de uma hora.

No caso do garoto se destacar (ou do esforço ser reconhecido), é convidado para compor a equipe da Série Prata. Um bom desempenho no campeonato da Série Prata pode render um convite ou período de experiência na equipe da Série Ouro. Fazer parte da equipe da Série Ouro até 12 ou 13 anos, segundos os pais, é capital para aprimorar os fundamentos e adquirir experiência, e, então, é chegado o momento de decisão: continuar no futsal e galgar no futuro um teste em uma equipe do campeonato estadual, ou numa equipe do campeonato nacional; ou encerrar a tentativa de se tornar atleta profissional e focar nos estudos. Caso a escolha seja a primeira, na ponta deste planejamento estão as equipes de futsal da Espanha, Portugal ou Itália, para onde são encaminhados os garotos que se destacam aos 17/18 anos. No ano de 2008 foram transferidos um total de 38 atletas para o exterior, sendo que 21 foram para Itália, nove para Portugal e seis para Espanha. Já nos dois primeiros meses de 2009 foram enviados mais 33 atletas para países estrangeiros, sendo que 24 foram para Itália ${ }^{13}$.

As equipes destes três países propiciam como remuneração para os recém contratados algo entre 3.500 e 5.000 euros, segundo o relato do professor 1. Como a maioria dos treinamentos é somente no turno da noite, propiciam tempo livre para continuar os estudos numa Universidade (isso é destacado pelos pais como um ponto fundamental em relação à educação dos filhos) ou até o exercício de outro ofício no turno diurno. Mas esta opção de jogar futsal é em grande parte para aqueles que obtiveram cidadania europeia. Outra opção é seguir o caminho junto aos clubes profissionais de futebol de campo, a partir dos 13/14 anos. Para os especialistas, o futsal possibilita maior contato com a bola, consequentemente a participação efetiva também aumenta, as crianças aprendem a jogar em espaços reduzidos e o raciocínio rápido, entre outros pontos, que são considerados vantajosos para quem pretende iniciar posteriormente a prática do futebol de campo (FreIRE, 1998).

Todo planejamento do desenvolvimento do potencial do jovem atleta é dependente do clube escolhido. Para os pais e professores, o clube tem participação efetiva no processo de aprendizagem e inserção social da criança. Segundo os próprios pais, quanto mais a criança permanecer no clube, jogar partidas amistosas e participar de campeonatos 
oficiais, melhor transcorrerá o processo. No Clube, que serviu de espaço par nossa pesquisa etnográfica, além dos treinamentos para os garotos da Série Ouro e aulas nas escolinhas para os garotos da Série Prata, no início do ano são programados vários jogos amistosos. Normalmente são contra equipes escolares ou equipes da região metropolitana que não participam de competiçōes oficiais. Ocorrem também alguns jogos internos, reunindo as crianças da Série Ouro e Prata (Diário de Campo, 08/04/2008). Para os pais esses jogos servem para analisar o potencial do seu filho e rivalizar-se com os demais. Torna-se um processo de aprendizagem para as crianças e também para os pais, que acabam reavaliando os planos para o futuro do filho na modalidade de futsal/futebol de campo ou mesmo refletindo se há algum futuro para a criança neste esporte (Diário de Campo, 15/04/2008). Esperançosos, os pais entendem que a aquisição de habilidades necessárias para prática da modalidade passa por um longo processo de aprendizagem pelos quais as crianças devem ser submetidas (Diário de Campo, 20/04/2008). Paralelo ao mundo do futebol, os pais apresentavam vários planos na área educacional. Sem exceção citam a necessidade dos filhos cursarem o ensino superior. $\mathrm{O}$ pai de Jonas (13 anos) comenta com outro pai que: é diferente de 25 anos atrás. Eu treinava todos os dias desde os 15 anos e tinha que estudar a noite. Cheguei a me profissionalizar, participei do campeonato estadual. [...] aos 22 anos machuquei o joelho. Vocês sabem... Naquela época não tinha operação/recursos para recuperar um jogador, então fui ser comerciante, porque não tinha estudo nenhum (Diário de Campo, 09/09/2008).

A grande maioria dos pais aponta para a necessidade de cursar uma universidade. Destacam que o acesso ao ensino superior é possível para uma camada maior da população brasileira desde a última década ${ }^{14}$ (Diários de Campo, 25 /11/2007; 04/12/2008; 06/05/2008).

Nesse processo dinâmico, as formas de conduta esportiva predominantes não aprendidas e predominantemente aprendidas, pendem fortemente em favor das últimas ${ }^{15}$. A conduta esperada pelos pais neste processo de aprendizagem é que seus filhos tenham contato com um planejamento pautado em exercícios sistematizados, e que isso lhes possa garantir uma vantagem muito grande sobre os demais garotos. Portanto, a ênfase é no comportamento amplamente governado por mecanismos aprendidos.

Após alguns meses de observação regular das aulas e treinamentos, é possível afirmar que o planejamento, à racionalização do tempo, à "lapidação" do atleta, entre outros, acentuam que os modos predominantes aprendidos de direcionamento comportamental no esporte futsal tornam-se mais importantes e indubitavelmente dominantes em relação aos modos não aprendidos. Especificamente ao que é relacionado ao talento: ser veloz, ágil, rapidez de raciocínio, etc. Tudo isso é enaltecido pelos professores, contudo a intervenção deles no processo de aprendizagem é muito mais destacada (Diários de Campo, 25/02/2008; 19/06/2008).

Surge uma nova hipótese, a de que para os garotos praticarem futsal/futebol de forma competitiva no futuro, existe uma condição "sine qua non": estar atrelado a uma dependência de aquisição de formas de conhecimento aprendidas como principal forma de orientação neste meio esportivo. Corroborando, sabe-se que a aprendizagem de uma criança se torna possível pela interveniência de dois processos: um processo biológico de maturação e um processo social de aprendizagem. Aqueles que acompanham durante uma temporada o progresso de um garoto, por meio de aprendizagem de gestos motores, dificilmente podem deixar de notar como este processo de aprendizagem está intimamente relacionado ao processo de maturação biológica e um processo social de aprendizagem ${ }^{16}$. Nota-se que o aprendizado sistematizado é destacado pelos pais como tanto necessário quanto possível (Diário de Campo, 18/02/2008). O que especialistas podem questionar é se esta precocidade na aprendizagem se faz tão necessária ${ }^{17}$.

Alguns dados observados podem ressaltar a dimensão entre talento e treinamento. O Clube pesquisado está filiado a Federação de Futsal do Estado, tendo os campeonatos geridos por essa entidade com duração de nove meses. Entre jogos e treinamentos, o clube ofereceu em 2008 um total de aproximadamente 187 horas na série Ouro e 146 horas na série Prata na categoria sub 7 e sub 9. $\mathrm{Na}$ categoria sub 11 e sub 13 perto de 300 horas. Comparado com outros investimentos que alguns pais citaram (Diário de Campo, 22/04/2008), as horas destinadas ao futebol são maiores que um curso anual de inglês, judô ou violão; por outro lado, são menores do que a carga horária de 800 horas anuais destinadas a educação regular nas escolas brasileiras. $\mathrm{Na}$ faixa etária da pesquisa (9-13 anos), os garotos têm que frequentar 200 dias letivos com duração de quatro horas diárias de ensino. Comparando com a Itália - destino de muitos dos jogadores de futsal - as horas aulas são de 40 horas semanais. Na faixa etária da pesquisa (9-13 anos), os garotos têm que frequentar 200 dias letivos com duração de quatro 
horas diárias de ensino. Portanto, o total de horas aulas é muito próximo ${ }^{18}$.

A filosofia do Clube, segundo seus professores, é de revelar jogadores (é fato que alguns jogadores de futsal e futebol de campo, que atingiram o triunfo nacional e internacional passaram pelo processo de aprendizagem neste Clube). De acordo com os professores, a crença no talento é relativizada; aparece em algumas conversas, mas é nítida a importância dada à aprendizagem sistematizada, das quais eles participam ativamente do processo. Os professores destacam que o trabalho desenvolvido no Clube se aproxima da "lapidação de um diamante": "Você tem que ter paciência, o garoto chega aqui com seis, sete anos, aí você trabalha todos os fundamentos a exaustão, faz por temporada mais 30 jogos em cada ano e lá por 16/17 anos já dá para ter uma boa noção. [...] é um processo longo um pouco diferente de uma fábrica" - afirma o professor número 2. $\mathrm{O}$ que se discute - além do biotipo do garoto e dos pais, assim como sua descendência europeia ou não - é como moldar o garoto, como destaca o professor 1 : "[...] o peladeiro ${ }^{19}$ tem habilidade, dribla fácil, [...] e não tem a mínima noção de jogo coletivo, em fazer parte de uma equipe de futebol" (Diários de Campo, 18/08/2008; 30/08/2008; 08/11/2008).

Áreas de aprendizagem e controle motor, psicologia são relembradas pelos professores nas conversas entre si e com os pais, muitas delas emaranhadas com um senso de prática, após vários anos de profissão, como narra o professor 2:

[...] olha, é possível fazer um gordinho jogar bola, mas aí vocês [os pais] têm que colaborar no aspecto da alimentação, pois três ou quatro horas semanais de treinamento não resolvem o problema dele. A genética ajuda no futebol, mas é diferente do basquetebol e voleibol que precisa dos gigantes, aqui [no futebol] há espaço para o baixo, para o alto, mas tem que treinar muito, muito... Vocês têm que entender que é necessário dar tempo aos garotos. Tem um garoto de oito anos aqui na escolinha, falei para o pai dele outro dia, ele é muito lento, mas é dedicado, inteligente, e faz todos os exercícios com muito prazer, então espere ele atingir 13/14 anos, vamos treiná-lo e deixá-lo muito mais veloz. Se vai dar certo ou não, realmente não sei, mas tem que esperar, estamos no caminho certo. É um pouco diferente do processo da fábrica, lá você controla melhor as variáveis, aqui (no Clube) são tantas variáveis, que você tem que contar com a sorte (Diário de Campo, 11/10/2008).

Os professores entendem que os fatores genéticos e as experiências motoras anteriores são importantes. Em encontros sociais no Clube, ou mesmo na lanchonete, logo ao lado do ginásio, foram registradas conversas informais entre os pais e os técnicos. Nestas, por várias vezes, os técnicos pediam para que os familiares não deixassem que "o mundo do futebol" fosse o único das crianças. $\mathrm{O}$ professor 3 comentou com um pai: "brinque com seu filho, vá empinar pipa, faça um carrinho de rolimã, leve ele ao cinema, [...] pode deixar que quando voltar de férias faço a parte chata nos treinos, pois o planejamento do ano que vem já está feito”. Com anos de prática, esse último professor confidenciou que empiricamente acredita que as experiências motoras fora das aulas de futsal (as brincadeiras, os jogos infantis) são essenciais para que as qualidades de um jogador possam florescer. Por mais que a mística do talento possa persistir e por vezes ser retomada pelos pais e os próprios professores, no Clube esse processo de aprendizado é considerado como o mais importante, pois só ter talento não basta, ou melhor, como expressaram alguns professores, "[...] o garoto pode ter talento, mas sem um trabalho de "lapidação", ele acaba virando "peladeiro" (Diários de Campo, 04/03/2008; 19/06/2008).

\section{Discussão}

Três horas por semana é o mínimo que as crianças que participam das atividades no futsal permanecem no Clube. Nota-se que o planejamento das aulas é uniforme entre os professores: uma hora e 10 minutos de treino técnico (domínio de bola, passe, condução, etc.) e 20 minutos de treino tático (posicionamento em quadra/coletivo).

A dinâmica da aula mostra coerência com o discurso dos técnicos. A genética e experiências anteriores podem favorecer o desempenho de algumas crianças, mas a ênfase do trabalho está centrada na aprendizagem do gesto e na repetição. Os técnicos entendem que a aprendizagem é fruto da repetição dos movimentos (por exemplo, foram contabilizados mais de 300 passes, em diferentes situações, durante um único treinamento da equipe da Série Ouro da categoria sub 11 e mais de 60 chutes a gol de cada atleta) e das experiências proporcionadas por eles. 
Soma-se ao treino de quadra às demais experiências que os garotos vivenciam fora do âmbito do futebol e o desenvolvimento maturacional, físico e emocional como parte principal do processo ensinoaprendizagem. Em certa ocasião, o técnico 2 citou conceitos de aprendizagem motora: "Trabalhamos primeiro com a perna dominante do garoto, depois que tal aprendizagem está sedimentada, então passamos para os exercícios do lado não predominante, pois é assim que aprendemos na Universidade. [...] a transferência fica muito mais fácil (Diários de Campo, 19/06/2008; 30/08/2008)"20. Os garotos ficam animados quando sentem a possibilidade de realizar movimentos que anteriormente só viam pela televisão. Chutar, passar, cruzar com a perna não predominante (na sua grande maioria as crianças são destras), é motivo de muita satisfação. "Há seis meses meu filho não chutava nem a dois metros de distância do gol com a perna esquerda, hoje a melhora é visível", confidencia o pai de Pedro. O pai do garoto refez seu planejamento inicial, entendeu muito rápido que seu filho estava nos primeiros passos de um longo processo de aprendizagem (Diários de Campo, 25/02/2008; 12/04/2008; 19/04/2008).

Apesar dos técnicos demonstrarem certo conhecimento dos fatores envolvidos no processo de formação do talento, MASSA (2006) afirma que não se observam na literatura científica, nas confederações e federações, ou mesmo nos clubes, estudos sistemáticos sobre a evolução dos atletas em variáveis relativas ao crescimento, desenvolvimento, maturação, treinamento e desempenho e, tão pouco, da interação entre esses processos, o que seria de grande valia para o estabelecimento de critérios fundamentados em cada modalidade esportiva. Durante o processo de formação, tais critérios seriam fundamentais para que houvesse a possibilidade de melhor correção e direcionamento dos futuros talentos em uma amplitude muito maior de variáveis inerentes a este processo.

Durante as aulas os professores acentuam constantemente a pressão psicológica e o desenvolvimento da parte física. Interromper a corrida, falta de empenho (ou como se diz na linguagem futebolística: fazer corpo mole) ou errar os movimentos é considerado algo desrespeitoso com o professor e com o grupo. Quando o erro aparece nos treinos repetitivamente, a bronca é contundente, principalmente em se tratando dos garotos da Série Ouro. O professor 2 relatou: "Chegamos ao extremo com os garotos porque em dia de jogo ninguém vai ficar com pena deles, nem os pais [...]. Ou eles se acostumam ou não têm futuro, já vi muito garoto habilidoso desistir, se não aguenta pressão aqui vai ter que conviver com ela na fábrica, no comércio, a vida é assim" (Diário de Campo, 11/10/2008). Suas observações são fruto de um modelo cultural da modalidade, cujo rendimento e eficácia são elementos em destaque (DaOlio, 1997).

De acordo com ArENA e BöHME (2000), o fato de dirigentes, técnicos, professores e pais esperarem "resultados imediatistas", através de uma boa atuação e resultados esportivos de seus jovens atletas em jogos e competições, pode provocar a perda da perspectiva de melhores resultados na idade adulta, mesmo com bons resultados em competições infantis e juvenis.

No geral e de forma menos contundente ao futuro dos filhos, os pais apontam para a necessidade de que a aprendizagem cobrada no campo esportivo seja expandida aos demais campos da vida. A educação é o ponto mais salientado ${ }^{21}$. Os progressos no futebol e na escola têm a mesma cobrança das famílias que foram observadas, e isso ocorre independente do capital econômico. A diferenciação é que as famílias mais abastadas conseguem oferecer cursos complementares como inglês, violão, informática e outros esportes, como as artes marciais. (Diário de Campo, 13/05/2008; 09/12/2008).

Pelas observações e conversas entre os pais, seria inoportuno afirmar que as horas despendidas com os treinamentos e com o esforço familiar para acompanhar os jogos e pagar as mensalidades possam representar o grande e único projeto familiar. Independente da classe social, os pais ressaltaram a necessidade e obrigação em ampliar as oportunidades dos filhos. No trabalho de observação foi possível diagnosticar a co-habitação de diferentes classes sociais, mas seria leviano apontar que a maioria das famílias pertence à determinada classe. Neste processo de "lapidação", cada família gastou em média cerca de dois salários mínimos e meio por ano (valor apontado pelos pais nas observações e confirmado em entrevista com coordenadores do Clube), sem contar o custo de transporte e material esportivo. Os esforços são em várias direções, ficar a madrugada inteira na fila para conseguir uma vaga numa escola pública de melhor prestígio, pagar cursos considerados fundamentais para inserção no mercado de trabalho, enfim, buscar alternativas que possam ajudar a formação do futuro cidadão. Dois exemplos mostram a preocupação dos pais e a busca num futuro educacional melhor. O primeiro é a procura por bolsas de estudos em escolas particulares. Dois garotos que frequentavam o Clube, por exemplo, ganharam bolsa integral numa escola particular devido ao fato de terem se destacado 
no campeonato da Série Ouro. Em 2010 irão jogar pela Escola que também participa da Série Ouro. O segundo exemplo é a participação de alguns garotos em curso preparatório visando o processo seletivo do Colégio Militar do Paraná. Instituição de renome, que oferta aproximadamente 50 vagas para alunos cujos pais não são militares (Diários de Campo, 25/11/2007; 25/02/2008).

Para alguns dos pais, a predileção pelo futebol acaba misturando-se à emoção de ver o filho em quadra. Assim, a iniciação esportiva do garoto passa a ser uma diversão familiar, pois o futebol é dinâmico/visível, aflorando sentimentos que dificilmente apareceriam nos cursos de informática ou inglês. Além disso, aventa-se a possibilidade de ampliar o leque social e propiciar ao garoto mais uma oportunidade que tem suas especificidades, tais como a possibilidade no futuro de ganhos astronômicos (Diários de Campo, 12/04/2008; 19/04/2008).

Mas o futebol não é a única aposta, como é explicado pelo pai de Roberto:

Não há nada de mal em trazer meu garoto aqui, numa idade que alguns dos meus familiares acham tão precoce. Eu me defendo dizendo que ele gosta. Ele gosta de movimento. Ele me disse um dia que gosta da sensação de correr e sentir o vento na cara, de se esquivar dos outros guris [...] eu e minha esposa nos divertimos, sofremos quando ele erra e gritamos muito quando ele marca um gol [...] então isso aqui não é só pra ele [...] nós aprendemos a nos relacionar melhor, não gritamos tanto com ele na quadra como no início do ano [...] e conhecemos um montão de gente, aqui tem filho de médico, motorista, padeiro, engenheiro, é assim, é a vida [...] (Diário de Campo, 02/12/2008).

Em suma, a preocupação dos pais não é apenas em propiciar o futebol aos filhos. Este esporte é parte importante na vida desses garotos, mas não é a única. A diferença parece estar na especificidade do esporte e as emoções que ocasionam. O futsal pode ter uma dinâmica que, em alguns momentos, lembra a lógica do trabalho: treinamentos otimizados, o cronômetro, a lapidação do material (humano) bruto, a fabricação (de um craque). Todavia, o esporte tem características próprias:

[...] nas modernas sociedades, o esporte veio a ser importante na identificação dos indivíduos com a coletividade à qual eles pertencem; isto é, na formação e expressão do seu "sentimento nosso" e "nós - eu". Através de sua identificação com times esportivos, as pessoas podem expressar sua identificação com a cidade que ele representa ou talvez com um subgrupo particular, como uma turma ou grupo étnico. Há razões para se crer que, num contexto complexo, fluido e relativamente impessoal da moderna sociedade industrial, associar-se ou identificar-se com um time pode prover as pessoas com um importante apoio de identificação, uma fonte de "sentimentos nossos" e um senso de pertencimento que de outro modo seria uma existência isolada ${ }^{22}$.

Foi possível identificar o despertar das emoçôes para os garotos, seus pais e familiares, ocupando conscientemente ou não uma parte central na busca desta atividade esportiva, devido ao fato de tal esporte desempenhar uma função de desrotinização e a necessidade de estar junto com os demais pais na torcida em dias de jogos.

$\mathrm{Na}$ maioria das vezes os garotos vêm da escola indicados por um professor de Educação Física ou somente pelo desejo do pai. Essas crianças, com cinco/seis anos, pouco conhecem das facetas do mundo do futebol, quiçá do futsal. Aos poucos os garotos começam a enfrentar um duro trabalho exaustivo e rotineiro na aquisição das habilidades motoras. O período aqui enfocado (dos cinco aos 13 anos) pode ser chamado de aprendizado dos fundamentos básicos desses esportes (FrEIRE, 1998). Muitos pais exploraram nas brincadeiras infantis jogos com bola. É corriqueiro os pais mencionarem a bola como o principal brinquedo da criança e da interação crianças/pais/familiares (Diário de Campo, 25 /11/2007). Num país onde o esporte mais popular é o futebol, não é difícil de imaginar que experiências motoras com a bola ocorram de forma frequente. Desde as idades mais tenras é comum, a ponto dos garotos terem a bola como brinquedo antes mesmo de saber andar (DAOLIO, 1997).

Outros pais procuram realizar-se pessoalmente por meio do possível sucesso do filho nessa modalidade (Diário de Campo, 25/02/2008). Não é o caso de perguntar se eles estão certos ao planejarem a vida dos seus filhos dessa maneira. Obviamente, isso é apenas uma suposição. Qual ser humano pode emitir julgamentos em tais assuntos? As ideias de lapidar ao longo de anos as ações motoras e psíquicas estão nos moldes da época, da racionalização da disciplina do trabalho incessante, da produção em série do controle cirúrgico dos acontecimentos, enfim, afinados com uma sociedade em que se vive, em vários momentos, estas situações. Os garotos observados crescem aprendendo que o sucesso financeiro e social se inicia muito precocemente, sendo que o processo de aprendizagem é fundamental - e 
para alguns uma oportunidade única - de ascensão social e de se alcançar a realização na vida (Diário de Campo, 25/02/2008). Até certo ponto, essa projeção/planejamento que os pais elaboram para seus filhos apresenta um caminhar em conjunto. Enquanto pequenos, ficar com os pais brincando de rolar, chutar, cabecear, rebater uma bola é um tanto prazeroso (Freire, 1998). Conforme vão crescendo e tendo seus pais e familiares por perto nos treinos e nos jogos, na assistência de partidas oficiais na televisão e nos estádios, proporciona às crianças certo ar de segurança ${ }^{23}$. O que é difícil de provar, é que sensibilidade e aparato motor para jogar futebol estejam presentes desde o nascimento. O entrelaçamento do processo maturacional em desenvolvimento e o processo social de aprendizagem, mostram a necessidade não só de aprender, mas de que os seres humanos devem aprender cada vez mais. Esse processo maturacional (biológico) e o processo social são interdependentes, o direcionamento da conduta não pode ser atribuído exclusivamente à natureza nem a aprendizagem (FrEIRE, 1997).

Cada sinal de aprendizagem dos fundamentos do futebol - desenvolvimento do talento - faz com que os pais acabem se realizando pessoalmente. Quando as crianças respondem positivamente os esforços dos pais de levar aos clubes e acompanhá-las no transcorrer deste processo; quando os pais vêem seus filhos absorvendo com rapidez e executando os exercícios complexos com perfeição, que às vezes excedem em muito as expectativas da própria família, transbordam lágrimas de admiração e alegria. Alguns familiares são astutos e prudentes, reconhecendo que o talento dos garotos possa gerar oportunidades futuras para ele e toda a família. Dessa forma, muitos procuram agir como verdadeiros managers dos garotos. Em determinados momentos, assumem a postura de professores/educadores, técnicos exaltados, conselheiros, empresários, e por vezes, de pai e amigo.

A aprendizagem do futebol desses garotos passa por um sistema rígido, um controle brutal sobre suas ações, emoções e dos procedimentos dentro e fora de quadra. No saldo positivo do resultado desta experiência, estão os estímulos motores e o controle psicológico que recebem nos jogos e treinamentos, e esses garotos são admirados por isso. Durante a observação dos jogos foram poucos os casos de conduta de pais depreciando os comportamentos dos filhos nos treinamentos e nos jogos. Sempre os garotos recebiam estímulos positivos dos seus progenitores. A Federação de Futsal obriga a cada final de partida que os jogadores se cumprimentem no centro da quadra, como sinal de respeito e integração, mas interessante como se tornou tradição entre os pais arremessarem muitas balas na quadra ao final de cada partida, onde vencidos e vencedores se misturam e se unem para pegar esse carinho da torcida. A admiração e estímulos positivos aos pequenos jogadores fazem parte do processo, planejados antecipadamente por alguns pais (Diários de Campo, 25/02/2008; 12/04/2008; 19/04/2008)24.

Sair das brincadeiras de futebol no próprio bairro e dos jogos nas escolas - muitas vezes adaptados por parte do professor de educação física - é o primeiro passo para desenvolver o talento. Os pais dos garotos de treze anos são categóricos quando afirmam que o talento do filho não teria se "cristalizado" caso não tivesse a oportunidade de vivenciar no clube o rígido programa de treinamento a que foi submetido. Romper com as brincadeiras e jogos adaptados e ter a experiência num clube formador é a forma mais adequada apresentada pelos pais para se desenvolver o talento do filho. É de se perguntar se os garotos, apesar de todo talento, teriam se "cristalizado", caso na infância e na adolescência, as experiências no clube não tivessem sido proporcionadas.

É possível observar que o comportamento em quadra e os gestos motores são aprendidos durante um longo processo que exige muito esforço e sacrifício, e que depende em parte do planejamento (em alguns casos esse planejamento chega a ser metódico) traçado pelos pais para sua vida. É evidente que o planejamento pode não surtir efeito, caso as oportunidades de aproveitar a riqueza de estímulos motores e psicológicos tenham sido desperdiçadas se os garotos a elas expostos não tiverem a necessária receptividade. Aqueles que estão a caminho do triunfo têm como ponto comum a familiaridade intensa e prematura com o futebol estabelecida no transcorrer do cotidiano: a bola como brinquedo, as partidas de futebol assistidas, o tempo despendido da família em levar e assistir os treinos e jogos, a promessa de um futuro promissor por meio dos imagináveis altos ganhos financeiros e a possibilidade de mobilidade social para cima orientando a vida dos garotos para uma direção muito específica, bem antes do que ocorre com os demais garotos que não são levados aos clubes.

Neste contexto, o do clube, os garotos são expostos a exercícios que valorizam a aquisição das habilidades motoras, por meio da aprendizagem através do ensaio/erro; os jogos internos propiciam um ajuste corporal e domínio do corpo em relação ao espaço e o tempo; e, finalmente, os jogos amistosos e oficiais com assistências numerosas (torcidas 
pró e contra) é um teste para o emocional. A energia desses garotos está concentrada, desde muito cedo em processos específicos de sublimação que, ao invés de se oporem ao processo de aprendizagem, o suportam e procuram criar novas situaçōes, ampliando as possibilidades de surpreender seus adversários. Isso explica em parte como é indissolúvel o vínculo entre a especialização, no futsal e no futebol, bastante prematura e o desenvolvimento humano geral ${ }^{25}$.

Conscientemente ou não os pais guiam os impulsos das crianças, orientando boa parte do seu cotidiano e suas fantasias para este dois canais: a busca pela prática do futsal e futebol e pelos conhecimentos proporcionados pela escola. A aprendizagem intensiva dos garotos envolve muitas possibilidades, mas é certo que o futebol torna-se a parte central na infância e na juventude de muitos deles, por meio de exaustivo trabalho - muito próximo das características de trabalho profissional nas grandes empresas.

Os garotos não são insensíveis aos pequenos gestos de apoio de seus familiares ou de afeto,

\section{Conclusão}

Embora o avanço da Educação Física na utilização de alguns conceitos e métodos das Ciências Sociais seja evidente, há muitas lacunas. $\mathrm{O}$ alerta sobre a necessidade de pesquisas que enfoquem o processo de formação do atleta vem das Ciências Sociais "[...] verificamos uma lacuna na literatura sociologia futebolística: tratase da ausência de estudos sobre o processo de formação do jogador de futebol" (Rodrigues, 2003, p.45). RoDRIGUES apresenta como objetivo mostrar que existe um claro processo envolvendo ensino e aprendizagem na formação do futuro profissional, em substituição as noçôes de simples dom ou vocação para se tornar jogador profissional. Ele analisa o processo de formação do Internacional no Porto Alegre a partir dos 10 anos. Corroboramos com sua análise e os resultados vão na mesma direção, mesmo que o foco da análise da nossa pesquisa tenha sido a configuração do cenário curitibano do futsal, esporte que serve para muitos jovens como trampolim para o futebol de campo, e por isso iniciam muito mais cedo.

MASSA (2006) também ressalta que jovens atletas que não abandonam a prática esportiva, mas que por terem vivenciado a inadequação no processo de formação - na maioria dos casos sem consciência do ocorrido - acabam por não atingir, no momento que deveria, o ápice da forma física, e consequentemente amizade, camaradagem e às emoções sentidas sempre compartilhadas com seus colegas em cada vitória ou derrota. Também das palavras de superação de seus professores, dos aplausos e vaias das torcidas, da cobertura da imprensa e de seus nomes divulgados nos sites da federação e dos clubes, das recompensas materiais como medalhas, troféus e outros como a distinção outorgadas pela Câmara Municipal a cada final de temporada aos eleitos como melhores jogadores (Diário de Campo, 09/12/2008).

A caminho do triunfo, os garotos são submetidos a um regime estimulante de aprendizagem, mas extremamente severo. Não é de se surpreender que logo tenham desenvolvidos uma sensibilidade aguda na parte técnica e tática do jogo. O fato de que uma aprendizagem, assim, especializada, os tenham capacitado a ter performances surpreendentes no futsal e no futebol, talvez seja menos surpreendente do que o fato delas causarem algumas desistências nos clubes, alguns garotos não se vergaram a esse tipo de processo de aprendizagem.

seu melhor resultado de desempenho. Ou seja, a criança foi detectada como talento, mas não foi acompanhada, desenvolvida e promovida da forma adequada para que, quando adulta, apresentasse o desempenho prognosticado na infância e/ou adolescência. Este fenômeno ocorre constantemente no processo que envolve o futuro jogador de futebol, principalmente no momento de definição se o mesmo reunirá as condições adequadas para se tornar um jogador da equipe profissional, ou não terá espaço nesta transição da base à categoria final, acabando por muitas vezes mudando de clube, ou até mesmo desistindo do esporte, frustrando as próprias expectativas, assim como de seus pais.

O objetivo foi investigar o planejamento e ações que os pais e clubes realizam com a intenção de criar possibilidade de aquisição de habilidades motoras, e potencializá-las, dando indícios claros de surgimento de um novo jogador. Dessa forma, os pais e professores misturam: a crença de que as crianças têm certo talento próprio, com a necessidade de lapidação por meio de técnicas que os clubes e seus profissionais têm capacidade e qualificação para tal.

No transcorrer do texto ressaltamos que durante a infância muitos garotos são levados a praticar o futebol numa perspectiva de opção profissional - mas 
não é única ganhando contornos e ares de sucesso imediato e futuro garantido. Neste caso específico, há uma diferença encontrada no estudo de ARAúJO (1980), que analisa oito jogadores profissionais na década de 80 , e, entre eles somente um desejava ser jogador profissional desde pequeno. Os sete demais entrevistados tinham o futebol apenas como diversão e, como ponto em comum, o fato de terem sido levados ao clube por meio de olheiros. Em nosso estudo, com idades mais tenras, pais, professores e atletas - estes últimos, por convencimento, repetição do discurso dos adultos ou mesmo vontade própria - apostam na aprendizagem do futsal como início de uma carreira bem sucedida no futebol de campo.

Confirmamos nossa hipótese de que a mítica do talento inato dá lugar à aprendizagem sistematizada como forma de se obter o triunfo, por meio da valorização do treinamento tático e técnico, assim como a valorização da repetição dos gestos. Como no estudo que EliAs (1995) sobre Mozart, também não é excluído o dom e o talento, porém, neste caso do futsal, tanto pais como técnicos consideram insuficientes na formação do futuro jogador. O clube é algo que substitui as os campinhos de bola e a aula sistematiza rigorosamente toma lugar da brincadeira de jogar bola.

Ao mesmo tempo, o estudo mostrou que os técnicos na sua totalidade e os pais se não na sua totalidade, a grande maioria, entendem a necessidade de diferentes planos profissionais para seus filhos. Abre espaço para desmistificar o mito que os pais e filhos ali estão pela única razão: a recompensa monetária futura e que consequentemente a esfera da educação escolar é deixada de lado. Durante as entrevistas e observaçôes, foi possível observar que nenhum dos 48 atletas tinham reprovado algum ano letivo; ao contrário em alguns casos, os garotos estavam em séries adiantadas.

A formação de atletas - ou poderíamos dizer a deformação das crianças - começam muito cedo. Diferente de outras profissōes, experimentar ser jogador de futebol é uma missão que alguns pais se colocam antes mesmo do filho nascer. A mãe de Roberson confessou que o nome do filho foi motivo de muita discussão, pois o pai queria muito que o garoto ao nascer tivesse o nome do artilheiro do campeonato brasileiro de 1999 (Diário de Campo de 29/11/2008).

Para quem vive numa sociedade industrializada, letrada e razoavelmente bem sucedida, é preciso um pouco de imaginação para fazer ideia do estilo de vida que especificamente estas crianças e adolescentes do mundo da bola são colocadas a prova diariamente. E esse é um exercício que vale a pena ser feito.

\section{Notas}

1. http://www.futeboldebase.com.br/noticia.php?id=260 acesso em 01set. 2010.

2. Sobre talento esportivo, Cf. BöHme (2001).

3. Kalleo (2009, p.84-5). Para uma leitura mais aprofundada sobre o processo de globalização e o futebol, consultar Marchi Junior e Afonso (2007) e Giulianotti e Robertson (2004).

4. Em recente matéria de capa da Revista Veja encontramos dados referentes às estratégias empreendidas para a "escalada do sucesso" assim como alguns tópicos específicos que se tornaram objetos de análise em vários campos do conhecimento, a saber, a mercantilização do esporte, a especialização precoce, o "internato" do futebol (condições favoráveis e desfavoráveis para o aprendizado e o desenvolvimento de uma carreira), as possibilidades de ascensão social vinda de países de pífia tradição no futebol, os critérios e ações dos "caçadores" de talento, a globalização e seus aspectos econômicos prescrevendo comportamentos e valores do iniciante e do profissional, entre outros. KaLLEO (2009, p.76-85).

5. Cf. Kalleo (2009, p.79).

6. SCAGLia (1999). Pode-se fazer, então, a seguinte analogia: o Brasil já foi bicampeão mundial de basquetebol e tinhase, desta forma, o dom divino para tal esporte; consequentemente as crianças já nasciam com o talento de encestar. E agora que o país não participa de três Olimpíadas e com resultados pífios nos Mundiais, já não nascem mais crianças com este dom. Talvez seja porque o Criador tenha direcionado o talento de nossas crianças nas últimas três décadas ao voleibol, esporte que o Brasil foi campeão Olímpico e Mundial na última década.

7. Cf. Kant (1974, p.67).

8. Para Hegel (1985), "gênio é aquele que tem o poder geral da criação artística bem como a energia para exercer tal poder com o máximo de eficácia. Tal poder e tal energia são, porém, essencialmente subjetivos, pois a produção espiritual só pode existir num sujeito consciente do que quer dos fins que se propõe, da obra que pretende realizar”. 
9. Cf. Bourdieu (1998).

10. O pai de "Carlos" tem formação técnica em Química. Nunca frequentou um curso Universitário. Jogou futebol até os 15 anos, quando foi inserido no mercado de trabalho. Sempre ressalta que jogaria em bons clubes do exterior caso tivesse prosseguido no ramo do futebol. Projeta no seu filho esta possibilidade de vida no âmbito do futebol, mas notou logo de início que ele teria que se esforçar mais. Desconfia se o filho vai ter essa mesma vontade de treinar e jogar futebol daqui alguns anos, então, paralelamente ao futebol projeta uma carreira de engenheiro para seu filho.

11. Nos campeonatos da Região Metropolitana, organizados pela Federação Paranaense de Futsal, há uma divisão entre Série Ouro (os mais talentosos) e Série Prata (os iniciantes). Isso ocorre na categoria sub 7, sub 9, sub 11 e sub 13. Passadas essas idades, os critérios seletivos aumentam, só restando a Série Ouro.

12. A pressão exercida funciona como um rito de passagem. Cf. DA MatTA (1997).

13. Disponível em: <www.cbfs.com.br> Acesso em 10 mar 2009.

14. A afirmativa dos pais condiz com a realidade já que a educação superior brasileira, que se manteve relativamente estagnada ao longo da década de 80 , retomou seu crescimento nos anos mais recentes, e tende a se expandir cada vez mais nos próximos anos. Este crescimento se deve, em parte, à grande expansão ocorrida no ensino médio, que tem crescido a taxa de até $20 \%$ ao ano em algumas partes do país, aumentando, desta forma, o número de candidatos nos cursos superiores. Alguns autores como Simon Schwartzman defendem a tese de que desde o início deste século que o ensino superior brasileiro já estava passando por uma importante revolução silenciosa, que poucos percebem em sua abrangência, mas que pode levar a um estágio muito melhor do que o atual. Cf. SCHWArTzMan (2000, p.13-30).

15. Cf. Elias, Norbert. Sobre seres humanos e suas emoções: um ensaio processual-sociológico. Publicado pela primeira vez na Revista: Theory, Culture and Society, v.4, 1987. Posteriormente publicado na Revista The body: social process and cultural theory, 1991.

16. Cf. Malina e Bouchard (2002).

17. Cf. WeInecK (2000) - em especial o Capítulo V: Juventude e esporte.

18. Disponível em: <www.mec.gov.br> e <www.istruzione.it>. Acesso em: 13 abr. 2009.

19. Termo utilizado para definir o atleta habilidoso e malandro. Este geralmente não respeita o técnico, e se presume que não vai chegar à categoria profissional caso não passe por um processo de aprendizagem nos clubes formadores (Diário de Campo, 19/06/2008).

20. O referido professor citou o livro de MAGILL (1989), Motor learning: concepts and applications como referência. Livro que foi traduzido para o português e utilizado nos cursos de Educação Física.

21. O Clube cobra os boletins bimestrais das crianças. Durante o período de observação houve cobranças, mas em nenhum momento algum garoto foi impedido de treinar por causa de notas baixas.

22. Cf. Dunning (1999, p.33).

23. A necessidade de ser amado e a segurança que Mozart sentiu no início do processo de aprendizagem são destacadas na obra de Elias (1995).

24. Id., ibidem.

25. Cf. Elias (1987).

\section{Abstract}

Formation proccess of indoor and outdoor soccer athletes: an ethnographical analysis

People say "each Brazilian citizen is born knowing how to play soccer". However there is a long way between the detection of a talented soccer player until the development of this kind of inborn aptitude. That is the reason of children start the practice of soccer earlier and earlier in schools and soccer-specific schools with the hope of being invited or selected to play soccer in any professional club. Since there is a great amount of children and adolescents starting on this trade it is reasonable to observe and understand how the social behavior inside these soccer-specific schools occurs. The aim of the present study was to observe the relationships between parents, teachers (coaches), children and adolescents related to the planning of soccer learning process and social insertion of the children, as well as to observe the parents and coaches social behavior within the sports environment. All practices and even 
speeches of young players, parents and coaches were registered on a field diary along one year in a traditional soccer club of Curitiba. Considering that the inborn talent may not be more important than the systematic soccer training process to be successful, we intend to show how the directions to reach the glory in soccer are planned (or not) since early ages.

UNITERMS: Soccer; Talent; Sports training; Pedagogical and family plan.

\section{Referências}

ARAÚJO, R.B. Os gênios da bola: um estudo do futebol como profissão. 1980. Dissertação (Mestrado em Antropologia Social) - Museu Nacional, Rio de Janeiro, 1980.

ARENA, S.S.; BÖHME, M.T.S. Programas de iniciação e especialização esportiva na grande São Paulo. Revista Paulista de Educação Física, São Paulo, v.14, n.2, p.184-95, 2000.

BÖHME, M.T.S. O talento esportivo e o processo de treinamento a longo prazo. In: De ROSE JUNIOR, D. Esporte e atividade física na infância e na adolescência: uma abordagem multidisciplinar. Porto Alegre: Artmed, 2001.

BOURDIEU, P. O poder simbólico. 2. ed. Rio de Janeiro: Bertrand Brasil, 1998.

CAMPESTRINI, G.R.H. A responsabilidade social na formação de praticantes para o futebol: análise do processo de formação em clubes brasileiros. 2009. Dissertação (Mestrado em Gestão do Desporto) - Universidade de Motricidade Humana, Lisboa, 2009.

DA MATTA, R. O carnaval como rito de passagem. In: DA MATTA, R. Ensaios de antropologia estrutural. 2. ed. Petrópolis: Vozes, 1997.

DA MATTA, R. (Org.). Universo do futebol: esporte e sociedade brasileira. Rio de Janeiro: Pinakotheke, 1982.

DAMO, A.S. Do dom à profissão: uma etnografia do futebol de espetáculo a partir de formação de jogadores no Brasil e na França. 2005. Tese (Doutorado) - Instituto de Filosofia e Ciências Humanas, Universidade Federal do Rio Grande do Sul, Porto Alegre, 2005.

DAOLIO, J. Cultura, educação física e futebol. Campinas: UNICAMP, 1997.

DUNNING, E. Sport matters: sociological studies of sport, violence and civilization. London: Routledge, 1999.

ELIAS, N. Mozart: a sociologia de um gênio. Rio de Janeiro: Jorge Zahar, 1995.

. Sobre seres humanos e suas emoçôes: um ensaio processual-sociológico. Theory, Culture and Society, v.4, 1987.

ELIAS, N.; SCOTSON, J.L. Os estabelecidos e os outsiders: sociologia das relações de poder a partir de uma pequena comunidade. Rio de Janeiro: Zahar, 2000.

FREIRE, J.B. Educação de corpo inteiro: teoria e prática da educação física. São Paulo: Scipione, 1997. Pedagogia do futebol. Londrina: Midiograf, 1998.

GIULIANOTTI, R.; ROBERTSON, R. The globalization of football: a study in the glocalization of the "serious life". British Journal of Sociology, v.55, p.545-68, 2004.

GUEDES, S.L. Subúrbio: celeiro de craques. In: DAMATTA, R. (Org.). Universo do futebol: esporte e sociedade brasileira. Rio de Janeiro: Pinakotheke, 1982.

HEGEL, G.W. Estética: o belo artístico e o ideal. 3. ed. São Paulo: Abril Cultural, 1985. (Os Pensadores).

KANT, I. Da arte e do gênio: crítica da razão pura e outros textos filosóficos. São Paulo: Abril Cultural, 1974.

KALLEO, C. Chuteiras que valem ouro. Veja, São Paulo, ano 42, n.19, 13 maio 2009.

MAGILL, R.A. Motor learning: concepts and applications. 5. ed. Iowa: C. Brown, 1989.

MALINA, R.M.; BOUCHARD, C. Atividade física do atleta jovem: do crescimento a maturação. São Paulo: Roca, 2002. MASSA, M. Desenvolvimento de judocas brasileiros talentosos. 2006. Tese (Doutorado) - Escola de Educação Física e Esporte, Universidade de São Paulo, São Paulo, 2006.

NEGRINE, A.S. Instrumentos de coleta de informaçóes na pesquisa qualitativa. In: MOLINA NETO, V.; TRIVIÑOS, A.N.S. (Org.). A pesquisa qualitativa na educação física: alternativas metodológicas. Porto Alegre: UFRGS/Sulina, 2004. PRONI, M.W. A metamorfose do futebol. Campinas: UNICAMP/Instituto de Economia, 2000.

RIAL, C. Os boleiros em Andaluzia: um estudo da imigração de jogadores de futebol brasileiro à Espanha. Brasília: MECD, 2004. Relatório de Pesquisa Capes. 
RODRIGUES, F.X.F. A formação do jogador de futebol no Sport Club Internacional (1997-2002). 2003. Dissertação (Mestrado) - Instituto de Filosofia e Ciências Humanas, Universidade Federal do Rio Grande do Sul, Porto Alegre, 2003.

O fim do asse e a modernização conservadora no futebol brasileiro (2001-2006). 2007. Tese (Doutorado) - Universidade Federal do Rio Grande do Sul, Porto Alegre, 2007.

SCAGLIA, A.J. O futebol que se aprende e se ensina. 1999. Dissertação (Mestrado) - Universidade Estadual de Campinas, Campinas, 1999.

SCHWARTZMAN, S. A revolução silenciosa do ensino superior. In: RIBEIRO, E.; SAMPAIO, H. O ensino superior em transformação. São Paulo: Núcleo de Pesquisas sobre Ensino Superior (NUPES/USP), 2000.

SOUZA, C.A.M. Difícil reconversão: futebol, projeto e destino em meninos brasileiros. Horizontes Antropológicos, Porto Alegre, ano 14, n.30, p.7-17, 85-111, 2008.

VELHO, G. A utopia urbana. 2.ed. Rio de Janeiro. Jorge Zahar. 1975.

WEINECK, J. Biologia do esporte. São Paulo: Manole, 2000. v.5: Juventude e esporte.

ENDEREÇO

Fernando Renato Cavichiolli

R. Frei Francisco Mont'Alverne, 263, sobrado 2 81540-410 - Curitiba - PR - BRASIL e-mail: cavicca@ufpr.br
Recebido para publicação: 22/09/2010

1.. Revisão: 22/ 12/2010

2a Revisão: 09/06/2011

3. Revisão: $15 / 08 / 2011$

Aceito: 26/08/2011 